\title{
O QUADRO DE PERSEGUIÇÃO À FEITIÇARIA NO MUNDO PORTUGUÊS QUINHENTISTA ATRAVÉS DA PRODUÇÃO DE DISCURSO PATRIARCAL E MISÓGINO
}

\author{
Marcus Viniciuis Reis ${ }^{1}$
}

\begin{abstract}
Resumo: Este trabalho busca identificar e analisar como foram produzidos e difundidos os discursos morais, exarados por instâncias religiosas e civis, responsáveis diretamente pela sustentação de determinados padrões de masculinidade e de feminilidade que vigoraram de forma hegemônica no mundo português do século XVI. Para tanto são analisadas as normas legais vigentes nesse contexto, como as Ordenações Manuelinas, além dos tratados morais e religiosos que contribuíram para a definição desses padrões. O Tribunal do Santo Ofício também constitui objeto de investigação, pois tratou-se de instância de poder que contribuiu decisivamente para a manutenção desses padrões ao intentar controlar as consciências religiosas dos católicos. A partir desses dois eixos, pretende-se investigar como a formatação do delito da feitiçaria nesse espaço foi acompanhado pelo processo de delimitação desses padrões, em que a figura da feiticeira representou a subversão de uma determinada ordem social.
\end{abstract}

Palavras-chave: Tribunal do Santo Ofício português. Século XVI. Unidade do gênero. Feitiçaria.

\section{THE WITCH HUNT IN THE PORTUGUESE WORLD OF THE 16TH CENTURY THROUGH THE PRODUCTION OF PATRIARCHAL AND MISOGYNIST DISCOURSES}

\begin{abstract}
This work seeks to identify and analyze how moral discourses were produced and disseminated, exerted by religious and civil organizations, directly responsible for the support of certain patterns of masculinity and femininity that were hegemonic in the Portuguese world of the 16 th century. In order to do so, we will analyze the legal norms in force in this context, such as the Ordenações Manuelinas, in addition to the moral and religious treaties that contributed to the definition of these standards. The Court of the Holy Office will also be the object of investigation, since it was an instance of power that contributed decisively to the maintenance of these standards by trying to control the religious conscience of the catholics. From these two axes, we intend to investigate how the formatting of the crime of witchcraft in this space was accompanied by the process of delimitation of these patterns, in which the figure of the sorcerer represented the subversion of a particular social order.
\end{abstract}

Keywords: Portuguese Inquisition. Century XVI. Gender unit. Witchcraft.

\section{LA CHASSE AUX SORCIÈRES DANS LE MONDE PORTUGAIS DU XVIE SIÈCLE À TRAVERS LA PRODUCTION DE DISCOURS PATRIARCAUX ET MISOGYNES}

Resumé: Ce travail cherche à identifier et à analyser la manière dont les discours moraux ont été produits et diffusés, issus d'organisations religieuses et civiles directement responsables du soutien de certains schémas de masculinité et de féminité qui étaient hégémoniques dans le monde portugais du XVIe siècle. Pour ce faire, nous analyserons les normes juridiques en vigueur dans ce contexte, telles que les ordinations manuélines, en plus des traités moraux et religieux ayant

\footnotetext{
${ }^{1}$ Doutor em História pelo Programa de Pós-Graduação em História pela Universidade Federal de Minas Gerais. Pertenceu ao Conselho Editorial da Revista Temporalidades, vinculada ao Programa de PósGraduação em História da UFMG. Também foi bolsista do Programa de Doutorado Sanduíche no Exterior, através da Universidade de Lisboa.
} 


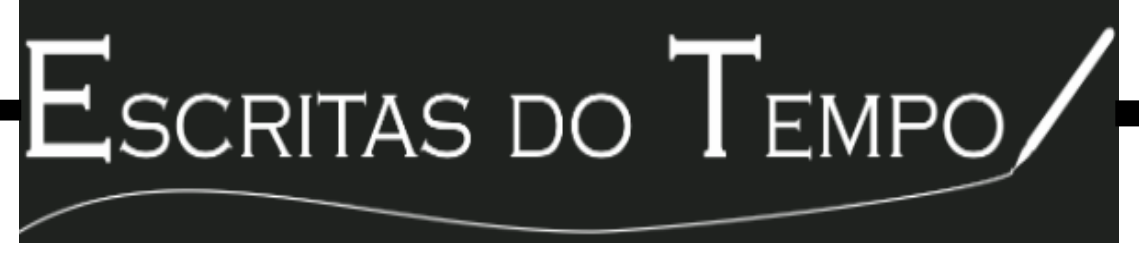

contribué à la définition de ces normes. Le Tribunal du Saint-Office fera également l'objet d'une enquête, car c'est un exemple de pouvoir qui a contribué de manière décisive au maintien de ces normes dans le but de contrôler la conscience religieuse des catholiques. À partir de ces deux axes, nous avons l'intention d'examiner comment la formulation du crime de sorcellerie dans cet espace s'est accompagnée du processus de délimitation de ces schémas, dans lequel la figure de la magicienne représentait la subversion d'un ordre social particulier.

Most-clés: Cour du Saint-Office. 16ème siècle. Unité genre. Sorcellerie.

\section{LA CAZA A LAS BRUJAS EN EL MUNDO PORTUGUÉS DEL SIGLO XVI A TRAVÉS DE LA PRODUCCIÓN DE DISCURSOS PATRIARCALES Y MISÓGINOS}

Resumen: Este trabajo busca identificar y analizar la forma en que se ha producido y difundido discursos morales, formalizados por las autoridades religiosas y civiles, responsables directos al apoyo a ciertos patrones de masculinidad y feminidad en la fuerza de hegemónica en el mundo portugués del siglo XVI. Para ello se analizan las normas legales vigentes en ese contexto, como las Ordenaciones Manuelinas, además de los tratados morales y religiosos que contribuyeron a la definición de esos patrones. El Tribunal del Santo Oficio también será objeto de investigación, pues se trató de instancia de poder que contribuyó decisivamente al mantenimiento de esos patrones al intentar controlar las conciencias religiosas de los católicos. A partir de esos dos ejes, se pretende investigar cómo el formato del delito de la brujería en ese espacio fue acompañado por el proceso de delimitación de esos patrones, en que la figura de la hechicera representó la subversión de un determinado orden social.

Palabras-clave: Tribunal del Santo Oficio. Siglo XVI. Unidad de género. Brujería.

\section{Introdução}

É possível afirmar que, entre os principais historiadores ${ }^{2}$ que se debruçaram na temática referente à feitiçaria e sua relação com o Tribunal do Santo Ofício português, há um consenso de que a perseguição a esse delito não foi inaugurada a partir do estabelecimento dessa instituição, em 1536. No contexto lusitano, um dos primeiros registros oficiais que visou condenar o uso de práticas correspondentes ao que se entendia por feitiçaria reside em uma carta régia atribuída a d. João I, datada do ano de 1385, cujo texto versava sobre a "proibição de práticas como adivinhações, encantamentos, 'lançar sortes', evocar o Diabo, dentre outras" (CALAINHO, 2008, p. 212). Também no reinado de d. João I, já em 1403, uma outra carta régia proibia a busca de tesouros "através do auxílio de varas, os círculos para invocação de demônios e a adivinhação pelo espelho" (BETHENCOURT, 2004, p. 259). Ambos os registros buscavam reunir uma diversidade

\footnotetext{
${ }^{2}$ Cabe citar, principalmente, a obra de Francisco Bethencourt, $O$ imaginário da magia (2004), bem como os trabalhos do também historiador português José Pedro Paiva, Práticas e crenças mágicas (1992) e Bruxaria e superstição num país sem "caça às bruxas" (1997). Para a historiografia brasileira, Daniela Calainho (2008) também chamou a atenção para a relação das instâncias civis com o delito da feitiçaria.
} 


\section{Escritas do Tempo}

de práticas - da adivinhação às relações com o Diabo - em um mesmo entendimento conceitual: a feitiçaria.

As Chancelarias Régias acolhiam uma série de registros que davam conta de indivíduos que, supostamente, realizavam práticas interpretadas a partir da noção de feitiçaria. E, mesmo com o avançar do século XVI e diante da crescente presença inquisitorial nesse debate, a diversidade dos debates para além do campo religioso se manteve. Vide as Ordenações Afonsinas e as Ordenações Manuelinas ${ }^{3}$, bem como a difusão de tratados médicos, catecismos e tratados de cunho moral, indicando que não apenas os inquisidores possuíam conhecimento e interesse em debater sobre esse tema.

Logicamente que, conforme ressaltado por José Pedro Paiva (1997, p. 19), todo esse painel de discussões não significou a construção de um quadro demonológico em Portugal, como é possível visualizar, por exemplo, na França. Nota-se a ausência de um verdadeiro fenômeno editorial referente à produção de escritos relacionados à feitiçaria para o contexto português. Além disso, Paiva também afirma que o século XVI ainda é mais lacunar quanto à essa suposta produção editorial, destacando a inexistência de qualquer publicação nesta época, embora deixe espaço para um suposto manuscrito redigido pelo frei Bartolomeu dos Mártires, intitulado Tractatus de superstitionibus. No entanto, cabe afirmar que, outras obras, quando trataram das moralidades ideais aos cristãos, acabaram se debruçando no assunto, demonstrando o conhecimento das autoridades portuguesas quanto às principais discussões que envolviam a demonologia e a feitiçaria no período.

Por outro lado, pode-se também afirmar que esses autores entenderam a atuação do Santo Ofício a partir de 1536 como marco fundamental para o processo de delimitação conceitual desse delito, integrando-o, ao longo das décadas seguintes, ao rol de heresias a serem combatidas por essas autoridades. Assim, quando assumiu a hegemonia na perseguição à feitiçaria (MARCOCCI, PAIVA; 2013, p. 381), o Santo Ofício português, por meio dos seus agentes, seguiu os mesmos pressupostos existentes à época a respeito da definição desse delito, bem como dos mecanismos a serem utilizados na identificação dos (as) praticantes. Brian Levack (1988, p. 8), por exemplo, sugeriu que, entre finais do

\footnotetext{
${ }^{3}$ Como destacou Francisco Bethencourt (2004, p. 260), é a partir destes dois conjuntos jurídicos que o "delito da feitiçaria apresenta um aumento substancial de sua tipificação". Além disso, a instância eclesiástica possui um peso de relevância nesse contexto, como as constituições do bispado de Évora, datadas de 1534 e que, no entender do autor, "são as mais desenvolvidas do século XVI sobre o problema da feitiçaria".
}

Revista Escritas do Tempo - vol. 1, n. 1, mar-jun/2019 - p. 72-98 


\section{Escritas do Tempo/}

Medievo e os primeiros séculos da Época Moderna, os principais teóricos se ancoraram em duas noções principais acerca da "definição europeia de bruxaria".

A prática do maleficium foi uma delas, entendida pelos tratadistas como quando algum indivíduo direcionava determinado ritual a outra pessoa sob intenção negativa. $\mathrm{O}$ segundo pilar, continua o autor, adquiriu maior força com o avançar do século XV, em que a figura do Diabo se tornou um dos principais condicionantes para a existência da "bruxaria". Para ele, a "bruxaria era, portanto, diabolismo, a adoração do Diabo [em que] ambos os tipos de atividades das quais as bruxas eram acusadas - magia e diabolismo estavam intimamente relacionados" (LEVACK, 1988, p. 9).

Os inquisidores portugueses também defenderam que, dentre os principais imperativos para a comprovação desse delito, constava a presença do Diabo, seguido do pacto diabólico. A noção de pacto predominante no universo inquisitorial lusitano foi, segundo José Pedro Paiva (1997, p. 17), contemplada em duas principais práticas: o "pacto tácito" e o "pacto expresso". O “caráter implícito", expressão do autor, caracterizou a primeira noção, em que, mesmo quando o indivíduo negava qualquer presença do Diabo nas práticas promovidas - como os ritos de cura, adivinhação, etc. -, ainda assim o pacto era concretizado, tendo em vista que esses prodígios só possuíam efeito por conta dessa figura, "que tinha vontade própria para nelas se poder imiscuir" (PAIVA, 1997, p. 39).

Acerca do "caráter expresso", ou explícito, este reúne os elementos que se tornaram clássicos na demonologia entre os séculos XVI e XVIII, ou seja, o contrato entre o indivíduo e as figuras diabólicas, a oferta e a recepção de poderes mediante a servidão como forma de celebrar esse acordo. Mais ainda, este pacto poderia ser encarnado numa completa solenidade, em que esse personagem aparecia "visivelmente, sentado num trono, rodeado pela corte de demónios" (PAIVA, 1997, pp. 39-40).

Conforme ressaltou Isaías Pereira (1976, p. 87), a feitiçaria foi alvo de intensos debates teológicos e jurídicos nesse espaço - inseridos no contexto de emergência da demonologia na Europa ${ }^{4}$-, sendo-lhe atribuído o caráter de "foro misto". Assim, e a partir dessa compreensão, pode-se concluir que as instâncias civis e religiosas assumiram o

\footnotetext{
${ }^{4}$ Stuart Clark (2006, p. 13;27) defendeu que estudar a demonologia é, por consequência, adentrar no campo da bruxaria/feitiçaria, analisando-as a partir de quais linguagens autorizaram as crenças sobre a realização dessas práticas.
} 


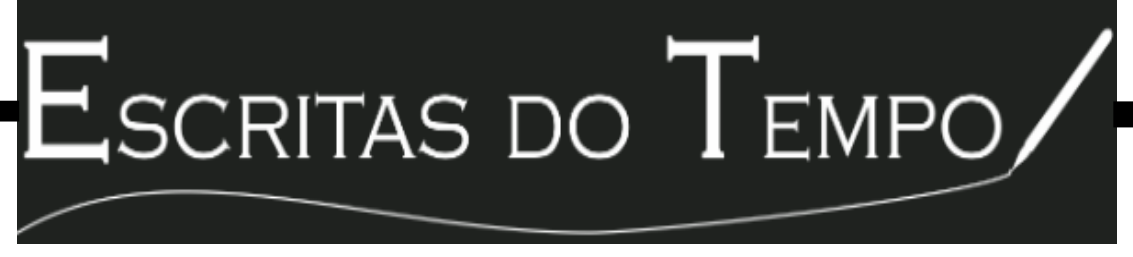

mesmo objetivo de conter o avanço das práticas ilícitas endereçadas ao sobrenatural, principalmente as que envolviam a participação do Diabo ${ }^{5}$.

Em termos cronológicos, foi entre os anos de 1541 a 1595 que o mundo português vivenciou sua primeira onda de perseguições contra os indivíduos acusados de promoverem esses pactos diabólicos. A instalação e o aparelhamento da estrutura inquisitorial não apenas no Reino, mas, também, nas possessões ultramarinas portuguesas, permitiram o alargamento do seu rol de atuação frente aos delitos existentes, dentre eles a feitiçaria (MARCOCCI; PAIVA, p. 42).

Esse primeiro momento foi caracterizado pelo elevado número de processos encetados pelas autoridades inquisitoriais ${ }^{6}$, ainda mais quando são consideradas as épocas anteriores, já que os relatos são mais esparsos. Por isso, esse período é o recorte temporal escolhido no presente trabalho, abrangendo cerca de 50 anos, exatamente o mesmo que coincide com as grandes ondas de perseguição que marcaram outras regiões do Ocidente europeu, mais especificamente as iniciadas nos Alpes ocidentais ${ }^{7}$, voltadas, nos casos de feitiçaria, principalmente contra as mulheres. José Pedro Paiva (1997, p. 17) afirmou, aliás, que os anos de 1580 a 1660 demarcam temporalmente o que foi "vulgarmente designado na historiografia europeia por "caça às bruxas"”, caracterizando um período particularmente violento.

Sob a ótica inquisitorial, o pacto demoníaco definiu as relações que os indivíduos - principalmente as mulheres, segundo as teorias da época - estabeleceram com o Diabo. Jean Delumeau (2009, p. 473), por exemplo, destacou a longeva associação do binômio mulheres/Diabo ao analisar o fenômeno de "caça às bruxas" no Ocidente europeu entre os séculos XIII ao XVIII. O autor ressaltou que esse binômio não foi exclusividade desse recorte temporal e espacial, mas apontou para esse período como o grande responsável por difundi-lo. Essa época, marcadamente cristã, "somou, racionalizou e aumentou as

\footnotetext{
${ }^{5}$ Sublinha-se, aliás, que a busca das autoridades por legitimar qual formato de perseguição seria o mais viável não foi exclusividade do contexto religioso português. Cf. PROSPERI, 2013, p. 377.

${ }^{6}$ Francisco Bethencourt (2004, p. 364-369) identificou 94 processos para esse recorte, sendo réus 68 mulheres e 26 homens. Desses, 61 foram processados pelo Tribunal de Évora, 24 pelo de Lisboa e 9 pelo de Coimbra.

${ }^{7}$ Carlo Ginzburg, em História Noturna (2001, p. 80), demarcou essa região como o espaço em que se consolidou, no século XVI, a "imagem do complô" contra as mulheres acusadas de bruxaria: "Pouco a pouco, a imagem da seita tornara-se mais específica: a apostasia da fé [...] fora sendo enriquecida com novos e macabros detalhes; o diabo, inspirador oculto das conspirações dos leprosos e dos judeus, saltara para o primeiro plano, em pavorosas formas animalescas. A sinistra ubiqüidade do complô, de início expressa pelo fluxo das águas envenenadas, afinal se traduzira, simbolicamente, na viagem aérea de bruxas e feiticeiros rumo ao sabá".
} 


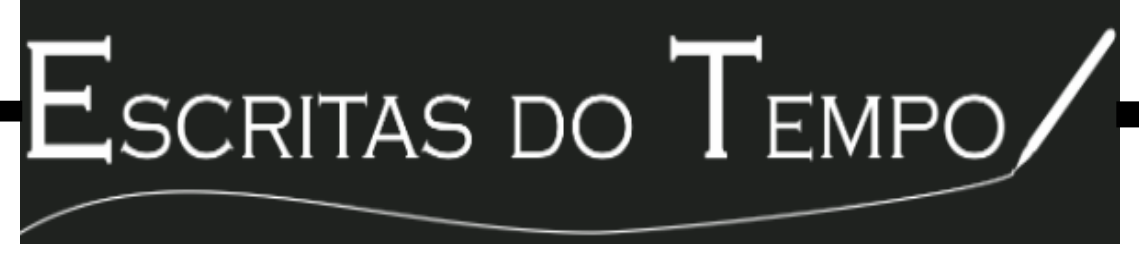

queixas misóginas" (2009, p. 473). Conforme defendeu Tamar Herzig (2010, p. 64), os escritos de Heinrich Kramer - que, inclusive, é autor de um dos principais tratados voltados à feitiçaria, o Malleus Maleficarum - devem ser considerados como exemplos do início de uma "feminização da bruxaria" a partir do século XIV. Já o medievalista Michael Bailey (2002, p. 120), ao defender a ideia de uma "feminização da magia", entendeu o século XV como o marco inicial da construção e difusão do conceito de "bruxaria satânica" e da associação majoritária entre "bruxaria e mulheres". No entanto, diferentemente de Herzig, o autor identificou nos escritos de Johannes Nider - autor do Formicarius - o ponto de partida para compreender como o fenômeno de "caça às bruxas" começou a ser generificado: "Nider foi a primeira autoridade clerical a discutir a bruxaria feminina em termos do seu gênero" (BAILEY, 2002, p. 125). Inserida nesse contexto, a feitiçaria ingressou na prática inquisitorial portuguesa em paralelo ao entendimento, cada vez mais sólido, de que caberia às mulheres a maior predisposição às influências diabólicas.

Diante das reflexões aqui levantadas e a partir do período definido acima, este trabalho pretende analisar a relação entre o Tribunal do Santo Ofício português e a produção dos discursos patriarcal e misógino a partir do contexto de atuação dos inquisidores frente ao delito da feitiçaria. O objetivo das instâncias religiosas e civis em não apenas teorizar, mas normatizar quais funções que homens e mulheres deveriam seguir para a manutenção da ordem social no mundo português, será o eixo de análise que relacionará ambos os temas. Esse mesmo interesse é o elemento que também sustenta a investigação sobre quais padrões de feminilidade e masculinidade predominaram à época e como as noções de patriarcado e misoginia são capazes de explicar a maior presença das mulheres como indivíduos processados pela Inquisição a partir desse delito.

Segundo Merry Wiesner-Hanks (2001, p. 50), a maior inserção dos historiadores no universo conceitual do gênero, possibilitou uma ênfase maior na problematização da "mulher" como uma categoria estável. ${ }^{8}$ Nas suas palavras, "na medida em que os historiadores das mulheres enfatizaram mais as diferenças entre as mulheres e se tornaram

\footnotetext{
${ }^{8}$ Judith Butler (2016, pp. 8;20), uma das principais teóricas do gênero, defendeu igualmente a necessidade de os pesquisadores problematizarem o caráter fixo das categorias existentes, principalmente as noções de "feminino" e "mulher". O intuito é retirar a estabilidade conceitual desses termos na medida em que os gêneros não devem ser considerados imunes às subjetividades, às escolhas individuais, e aos contextos históricos de dominação masculina. Sendo assim, não há uma base universal acerca do feminino, ou um sujeito universal "mulher".
} 


\section{Escritas do T EMPo/}

cada vez mais autocríticos, começaram a se perguntar se 'mulher' era uma categoria analítica válida". Por essa razão, deve-se considerar não somente o fato de que estruturas de gênero variam conforme os contextos, mas, também, os padrões de feminilidade e masculinidade. Trata-se, enfim, de defender o entendimento de que o patriarcado é aspecto essencial para a compreensão do fenômeno de caça às bruxas uma vez que as sociedades no período estiveram inseridas em relações de poder generificadas (BARSTOW, 1988, p. 50).

\section{Masculinidades e Feminilidades imaginadas: a literatura jurídica no mundo português}

Este item investiga como as noções de masculinidade e feminilidade foram definidas no âmbito da produção jurídica pertencente ao mundo português, buscando restringir esse debate ao século XVI. Defende-se, portanto, a existência do patriarcado como um conceito e, mais ainda, como uma "forma historicamente específica de organização e exercício do poder político, legal, social, econômico e cultural que, geralmente, privilegiam os homens sobre as mulheres" (ROWLANDS, 2003, p. 453).

Busca-se discutir, assim, como as funções voltadas aos homens e, principalmente, às mulheres, foram demarcadas de modo hierárquico, sob traços patriarcais e misóginos, e como cada prescrição direcionada a ambos influenciou diretamente, e sob um caráter relacional, na construção das noções de masculinidade e feminilidade que se tornaram hegemônicas no período. Também discute como as instâncias civis trataram do delito da feitiçaria, ao qual a produção de discursos voltados à normatização das mulheres se atrelou diretamente.

Assim, conforme proposto por Isabel Drumond Braga e Maria Mourão (2015, p. 87), entende-se que a compreensão de toda a estrutura organizacional e funcional referente a esse contexto está atrelada à análise de como as categorias de homem e mulher foram construídas juridicamente. Também defende que essas categorias pautaram as diversas relações sociais do período, sendo necessário compreender e analisar quais foram suas influências no processo de delimitação das hierarquias no mundo português à época.

Por essa razão, é necessário investigar os símbolos culturais que constituíram os alicerces não apenas dessas hierarquias sociais, mas, também, das categorias normativas que contribuíram para o entendimento jurídico sobre o que significou "ser mulher". Assim, será possível desenvolver os pressupostos levantados por Joan Scott (1995, p. 


\section{Escritas do Tempo}

312), em que a autora salientou a importância de os pesquisadores analisarem como os símbolos culturais representativos do feminino são evocados nos mais diversos contextos e como os conceitos normativos a esse respeito são estruturados.

As principais características atribuídas às mulheres, e referentes aos papéis sociais prescritos a elas nos tratados morais e na literatura jurídica que circularam ao longo do mundo português, podem ser resumidas na seguinte sentença: "boa mãe, boa dona de casa, boa esposa" (BRAGA; MOURÃO, 2015, p. 89). Os verbetes de dicionários são, por sua vez, exemplos dos discursos que, à época, buscaram delimitar o binômio masculino/feminino, sendo sustentado sob a dicotomia e a exclusão das mulheres dos diversos espaços sociais.

Baseando-se no primeiro dicionário da língua portuguesa, de autoria de Raphael Bluteau, datado dos primeiros quartéis do século XVIII, Isabel Drumond Braga e Maria Mourão destacaram essa oposição, afirmando que a construção desse binômio foi visível no discurso proverbial, recaindo ao universo doméstico o principal espaço de presença feminina, enquanto que, aos homens, a esfera de prescrições foi muito mais alargada e complexa: "Eis alguns dos exemplares retirados: "A mulher de bom recado enche a casa até o telhado'; 'A mulher e a gallinha, com sol recolhida'; 'A mulher de bondade, outrem fale e ella cale'; 'A mulher mal toucada, ou é formosa, ou mal casada'; 'A mulher, o fogo e os mares são três males' (Bluteau, 1716, p. 546)" (2015, p. 89).

A ideia de "homem social", expressão utilizada pelas autoras, é outro exemplo, já que a sua definição no contexto português foi entendida por dois vieses: referia-se ao "ser humano ou homo", no qual o feminino era englobado (senão silenciado), ao mesmo tempo em que caracterizava o gênero masculino (BRAGA; MOURÃO, 2015, p. 89-90).

Ao tratarem da obra de António Delicado, intitulada Adagios, Proverbios, Rifãos, e Anexins da Lingua Portugueza, ambas as autoras notaram o mesmo padrão encontrado nos provérbios presentes no dicionário de Bluteau, ou seja, uma predominância significativa de termos favoráveis e desfavoráveis às mulheres e, mais ainda, que representavam o próprio contexto normativo existente no Antigo Regime português:

Quanto ao pendor conceptual, reportado nos enunciados afectos ao parâmetro "favorável", os predicados femininos emergentes são induto-res do cumprimento da norma e de boas práticas, sobretudo os que têm que ver com: diligência - "A boa fiandeira, de S. Bartholomeu toma a véla e a mais boa da Magdalena"; "A mulher de bom recado enche a casa até ao telhado"; bondade - "A mulher boa prata é que muito soa", "A mulher de bondade, outrem fale e ella cale". (BRAGA; MOUR ÃO, 2015, p. 93) 
[...] são expressivos os que retratam o género feminino com desconfiança, menosprezo e preconceito, como se pode avaliar pelos exemplos: "A mulher e o pedrado quer-se pisado"; "Aquella é boa e hon-rada, que está viúva sepultada"; "Da má mulher te guarda, e da boa não fies nada"; "Do mar se tira o sal, e da mulher muito mal"; "Não crieis ga-linha, onde a rapôsa mora; nem creias a mulher, que chora"; "Aquella é bem casada, que não tem sogra nem cunhada". (BRAGA; MOURÃO, 2015, p. 94)

Quanto à literatura jurídica portuguesa, predominou o interesse dos seus protagonistas em construir um consenso no qual as obras e reflexões por eles produzidas deveriam compreender essencialmente a noção de que o masculino englobava o feminino. A busca por esse consenso pode ser justificada diante da predominância no período de um princípio básico pelo qual o masculino abrangia o feminino, ou seja, "a cabeça [evocava], naturalmente, todo o corpo" (HESPANHA, 2010, p. 103).

O contrário não se manifestava na medida em que, seguindo a mesma lógica, os juristas não consideravam que o elo mais fraco, o corpo, pudesse governar o elo mais importante, a cabeça. A “feminilidade", termo utilizado por Hespanha, só assumiu protagonismo nos textos jurídicos em ocasiões muito específicas, em que o legalismo genérico não se mostrava capaz de incorporar o feminino em uma unidade masculina. ${ }^{9}$

Interessada nos códigos legislativos portugueses, principalmente os que vigoraram entre os séculos XV e XVI, Raquel Patriarca (2002, p. 125) afirmou que, se não são as melhores fontes para retratar a vida cotidiana das mulheres, as Ordenações possibilitam ao pesquisador compreender a visão que as sociedades tinham para com as mulheres e o ordenamento jurídico construído para que essa visão assumisse um viés hierarquizante e masculinista.

Promulgadas durante o reinado de D. Manuel, em 1521, as Ordenações Manuelinas não apenas reafirmaram uma série de prescrições direcionadas às mulheres e já presentes nas Ordenações precedentes, as Afonsinas, como as ampliaram, tornando mais nítido como o padrão de feminilidade almejado pelas autoridades esteve atrelado aos ideais de submissão feminina aos homens. Cita-se, por exemplo, a preocupação em definir o papel das mulheres nos antecedentes da vida conjugal, sendo delegado aos pais a função de decidir o futuro de suas filhas nos assuntos matrimoniais.

\footnotetext{
${ }^{9}$ Um dos principais exemplos apontados por António Manuel Hespanha (2010, p. 105) em que havia a necessidade de uma escrita mais específica para as mulheres, consiste na questão relativa à sucessão dos bens relacionados aos castelos, feudos ou às jurisdições. De acordo com o autor, era tão absurdo no período que mulheres tivesse direito à sucessão que, ao designar "filhos" no testamento, entendia-se que o pai naturalmente se referia aos seus descendentes homens.
} 


\section{Escritas do T EMPo/}

Quando entraram em vigor, as Manuelinas não apenas reafirmaram essa condição, como buscaram clarificar a ausência do direito feminino quando as questões patrimoniais estivessem presentes, proibindo que as mulheres participassem ativamente da herança salvo em situações de doação ou mesmo por mercê do monarca (PATRIARCA, 2002, p. 127). Sendo assim, o domínio público foi entendido como espaço masculino de direito, muito por conta desse conjunto jurídico ter consolidado um ordenamento social pautado na manutenção da honra feminina atrelada ao enclausuramento das mulheres na vida doméstica.

É no quinto livro dessa documentação que pode ser observado o maior número de títulos que versam sobre o cotidiano das mulheres, principalmente nas questões envolvendo as relações ilícitas com os homens. Assim, do Título XIII ao XXIX estão presentes as preocupações dos juristas desde com homens que, por ventura, dormissem com qualquer mulher pertencente à sua parentela ${ }^{10}$, aos religiosos que frequentemente mantinham relacionamentos que, vale lembrar, eram proibidos.

Há, também, uma relativa preocupação referente aos episódios envolvendo homens que dormissem com mulheres casadas ou mesmo "Do que dorme por força com qualquer mulher, ou trata dela, ou a leva por sua vontade". Neste caso, a pena de morte era prevista como punição, mesmo se houvesse casamento após o ato sem consentimento. ${ }^{11}$ Nota-se, portanto, como o casamento aparece nessa literatura como uma instituição a ser salvaguardada pelas instituições, pois era encarado por esses personagens como sinônimo de estabilidade jurídica e social para as mulheres. A vigência desse sacramento como obrigação religiosa e social permitia evitar os possíveis desregramentos morais advindos da vida de solteiro (LENCART E SILVA, 1993, p. 62).

A "honra dos pais", presente no segundo livro, é um dos melhores exemplos para a compreensão da literatura jurídica como importante espaço que se preocupou com a regulação da vida das mulheres, pretendendo torná-las subservientes ao contexto de normatização de suas vidas. Nos casamentos clandestinos, o texto previa que as mulheres seriam meeiras, ou seja, teriam direito à metade dos bens adquiridos junto ao cônjuge,

\footnotetext{
10 "Toda pessoa de qualquer condição que seja, que dormir com sua filha, ou qualquer outra sua descendente, ou com sua mãe, ou com qualquer outra sua ascendente, sejam queimados ambos, e feitos por fogo em pó”. Cf. Ordenaçoens do Senhor Rey D. Manoel. Livro II. Título XIII, p. 50.

11 "Todo homem de qualquer estado, e condição que seja, que forçosamente dormir com qualquer mulher, posto que escrava, ou mulher que ganhe dinheiro por seu corpo seja, morra por isso". Cf. Ordenaçoens do Senhor Rey D. Manoel. Livro II. Título XIIII, p. 52.
} 


\section{Escritas do Tempo/}

desde que a relação fosse comprovada pela Igreja. ${ }^{12}$ Além disso, era necessária a presença de um tutor, fosse ele marido ou pai, pois seriam os responsáveis por legitimar a "pública voz", ou seja, de que havia uma união capaz de referendar a condição de meeira para a mulher. Por essa razão, afirma-se que o estatuto jurídico das mulheres e as suas formas de acesso a determinados direitos, prescritos na literatura jurídica da época, estiveram visivelmente atrelados às relações de poder em que a figura masculina buscava constantemente a reafirmação do seu protagonismo.

Os limites jurídicos, quanto à sua abrangência e proteção social para com as mulheres, também são visíveis nas Ordenações Manuelinas, conforme destacou Maria Lencart e Silva (1993, p. 66), defendendo que o pesquisador considere que as legislações da época apresentavam uma série de subdivisões a respeito das mulheres: "mulheresposa, mulher-mãe, a mulher-adúltera, a mulher viúva". A ausência por parte dos juristas portugueses em tratar o gênero masculino a partir dessa mesma lógica, continua a autora, pode ser justificada pelo modo como os homens conscientemente buscaram se posicionar na vida social, regulando-a e prevalecendo o interesse em definir um lugar de predominância e destaque a si próprios (LENCART E SILVA, 1993, p. 53). As subdivisões que foram colocadas para as mulheres deixam claro o papel de subserviência das mesmas e a restrição de sua atuação ao universo doméstico.

Tendo em vista os antagonismos e silenciamentos por parte dos juristas frente às mulheres, também foi possível identificar algumas diferenças a respeito dos direitos e das seguranças que as mulheres tinham acesso conforme a sua condição financeira, sua origem, e sua condição social. Cabe lembrar que elas estavam inseridas em uma sociedade na qual as diferenças hierárquicas sustentavam as relações entre os indivíduos. Assim, a mulher que pertencesse aos estratos mais ricos do mundo português, possuiria um trato diferenciado em relação à mulher de ascendência cristã-nova, ou mourisca.

Ao mesmo tempo, o fato de os juristas também apontarem para essa diferença, possibilita-nos relativizar a existência de uma prática hegemônica interessada em consolidar uma dada visão a respeito da mulher ideal. Outras mulheres, como as cristãsnovas e as mouriscas, também circularam no mundo português e estiveram distantes das prescrições jurídicas e religiosas hegemônicas.

\footnotetext{
12 “"...] se não provarem que foram recebidos à porta da Igreja, ou por licença do Prelado como dito é, ou não provando como estão em pública voz, e fama de marido e mulher, e em casa teúda e manteúda, ou em casa de seu pai, ou em outra casa onde estiver, não serão meeiras”. Cf. Ordenaçoens do Senhor Rey D. Manoel. Livro II. Título XLVII, p. 237.
} 


\section{Escritas do Tempo/}

É, portanto, impensável compreender a lógica não apenas jurídica, mas social, inerente ao Antigo Regime português, descolada das variadas estruturas normativas que nortearam a diferenciação entre homens e mulheres sob uma base hierárquica e, ressaltase, masculina. Com base nas Ordenações Manuelinas, é possível concluir que, para o século XVI, predominou na literatura o entendimento de que o masculino, mesmo quando o feminino era assunto principal das discussões entre os juristas, prevaleceu como sistema interpretativo.

A honra feminina foi invocada como argumento a fim de sustentar uma ordem patriarcal, ainda que a superfície desses textos possa indicar uma preocupação das autoridades com a segurança das mulheres. Assim, as imagens referentes a elas foram resultado de um saber jurídico que as enxergava sob a ideia de "fraqueza, debilidade intelectual, olvido e indignidade" (HESPANHA, 2010, p. 105).

Pode-se dizer, assim, que predominou nesse contexto uma estrutura de poder em que um dos principais objetivos, ao propor um ordenamento social, consistiu em perpetuar a chamada "heterossexualidade compulsória” (BUTLER, 2016, p. 57). Ou seja, na medida em que a construção do gênero é acompanhada do interesse em torná-lo uma noção unitária, capaz de consolidar o masculino/feminino como um binarismo de gênero e como dispositivo de controle, o mesmo contribui diretamente para a manutenção de toda uma condição normativa decorrente dessa relação.

Por consequência, tem-se a construção e a manutenção de hierarquias que, para o período analisado, visaram essencialmente a reprodução das noções de inferioridade e de submissão nas quais as mulheres deveriam ser condicionadas como forma de manutenção de uma ordem social. Por sua vez, aponta Butler, esse binarismo gera, também, o interesse das estruturas de poder em naturalizar essa estrutura hierárquica, tornando-a uma ilusão para aqueles que seguem essas prescrições. Além disso, tendo em vista que o gênero é construído a partir de uma performance cotidianamente repetida e através das estilizações do corpo, inserido numa estrutura que busca regular as relações sociais que homens e mulheres constroem, cabe ao pesquisador perceber qual noção de "mulher" foi definida sob essa pretensão hegemônica e, principalmente, masculina.

Diante dessas considerações, entende-se que o padrão de feminilidade predominante no Antigo Regime português esteve atrelado às diversas instâncias de poder responsáveis por sua produção e difusão - representadas por homens interessados na manutenção da ordem social que lhes fosse vantajosa. Como consequência, foi produzida 


\section{Escritas do Tempo/}

uma variedade de arquétipos em que imperaram as noções de honra, castidade e moralidade como aspectos sustentadores de uma versão hegemônica e idealizada a respeito das mulheres. A diferenciação entre os sexos passava, assim, por uma preocupação em determinar as diferenças biológicas entre masculino e feminino, além de reafirmar os papeis que deveriam pertencer aos homens e às mulheres a partir de ideais hierarquizantes.

A manutenção desse binarismo carregava consigo um interesse normativo. A própria defesa da família como uma instituição capaz de resguardar a ordem social foi, segundo Merry Wiesner-Hanks (2001, p. 25), uma experiência generificada. Noivas, esposas, mães: talvez estas três condições resumam as construções pretendidas pela masculinidade hegemônica acerca das mulheres no período analisado. Em uma síntese a respeito da presença feminina nas sociedades de Antigo Regime, Maria López-Cordón (1994, p. 80) foi pontual ao caracterizar esse contexto: "ordem e limite, estes são os extremos concretos que encerram a condição da mulher em um tempo determinado". O padrão de feminilidade autorizado nos discursos jurídicos foi construído sob o intuito de definir esses extremos.

\section{A moralidade católica e a definição dos papeis sociais no mundo português}

A condição natural das mulheres à submissão foi reafirmada constantemente pelos religiosos e encarnada, inclusive, nas hierarquias católicas, no qual o acesso delas aos mais altos cargos era vedado pela legislação canônica. Segundo Lyndal Roper (2005, p. 38), há uma considerável concordância entre os historiadores de que o período referente às reformas religiosas - protestante e católica - marcaram a transição para uma nova forma de patriarcado nas sociedades em que essas reformas foram influentes.

Nesse contexto, prevaleceu com maior força o discurso de que a predisposição ao trato ilícito com o sobrenatural, essencialmente representado na figura do Diabo, se daria com maior recorrência entre as mulheres, retratadas como seres de fácil persuasão. Era necessário, portanto, regular seus comportamentos, seus corpos, sua sexualidade e, não menos importante, a sua religiosidade. Desse modo, não apenas a jurisdição civil assumiu peso nessa preocupação, visto que uma série de tratados morais foram escritos por religiosos interessados na normatização referida.

Assim, o intuito deste item consiste em analisar a circulação desses tratados morais no mundo português, identificando as principais obras, discutindo o teor dos seus 


\section{Escritas do Tempo}

argumentos, bem como os modelos de masculinidade e feminilidade defendidos por esses discursos.

Se é possível falar de uma linguagem da feitiçaria, aos moldes dos pressupostos de Stuart Clark ${ }^{13}$, essa é composta obrigatoriamente pelos discursos produzidos entre o Medievo e a Modernidade europeia em relação aos papéis sociais prescritos para as mulheres, e como esses papeis foram elaborados sob uma atmosfera de insegurança corrente nesse período, concomitante ao processo de demonização da figura feminina. Entender as linguagens que embasaram a crença na feitiçaria é levar em consideração não apenas o peso jurídico e secular nesse processo, mas a existência de uma ambiguidade de longa duração acerca das mulheres e que se confunde, por vezes, com a própria consolidação do catolicismo como religião no Ocidente Europeu.

Os arquétipos construídos pela literatura moralista católica a respeito da mulher não fugiram muito dos discursos presentes à época no âmbito secular. A honra e a moral religiosa foram pilares comuns aos olhares civis e religiosos no intuito de determinar o ambiente doméstico como espaço em que as mulheres manteriam tais condições. A mulher que não exercesse a função social prescrita pelos códigos morais - e amplamente vinculada ao universo doméstico - foi interpretada como uma figura alheia aos ideais préconcebidos, tornando-se ameaça à manutenção da moralidade, das estruturas normativas, além da legitimidade do discurso de submissão feminina à presença dos homens.

Exemplo desse discurso moralista e religioso pode ser visualizado a partir da obra do frei Heitor Pinto, Imagem da vida cristã, publicada em 1563. Nesse tratado, o frade buscou reafirmar as hierarquias sociais existentes entre homens e mulheres e como elas refletiam na vida conjugal, sendo o matrimônio um espaço de reprodução das diferenças e de submissão das mulheres, uma vez que a ordem social dependia dessa forma de organização:

Verdade é que, ainda que a mulher quanto ao matrimónio seja igual ao marido, contudo, no que toca à disposição e governação da casa e fazenda, o marido é a cabeça da mulher, como o diz S. Paulo na Primeira aos Coríntios. Que a mulher deva ser subjeta ao marido, dizem-no S. Jerónimo sobre a Espístola a Tito, Santo Agostinho no livro das Questões do Génesis, Santo Ambrósio no Hexamerão [...] mas não como escrava, senão como companheira: não será sujeição servil, mas social. A mulher não há de dominar sobre marido: por isso não foi formada da cabeça de Adão: nem deve ser desprezada dele como escrava: por isso não foi formada dos pés: mas há de ser companheira do marido: por isso foi formada da costa, que está no meio do corpo. [...] os quais todos afirmam que a mulher deve

\footnotetext{
${ }^{13}$ Para o autor, "a linguagem autoriza qualquer tipo de crença". Cf. CLARK, 2006, p. 27.
} 
guardar ao marido grande lealdade, e ser-lhe subjeita: e honrada dele como companheira: e que ambos se hão de ter grande amor um ao outro. (PINTO, 1958, p. 38)

Esse longo excerto é permeado tanto pela tradição interessada em reafirmar a sujeição das mulheres à governança masculina, como para o forte apelo bíblico que uma série de tratados religiosos lançaram mão a fim de justificar esse caráter. Ressalta-se, também, que a invocação de São Paulo como suporte bíblico não é uma novidade trazida por esse autor. Essa mesma associação é encontrada em trabalhos do mesmo período e até mesmo de épocas anteriores, muito por conta de o mesmo apóstolo, segundo Jean Delumeau (2009, p. 469), ter encarnado a “origem das ambiguidades do cristianismo em relação ao problema feminino [...] [situando] a mulher cristã em uma posição de subordinação simultaneamente na Igreja e no casamento". Assim, a honra direcionada à figura feminina era vinculada diretamente à obediência que as mulheres deveriam construir para com seus maridos, tendo no companheirismo, na retidão e no respeito, alguns dos elementos decorrentes desse entendimento.

Em trabalho recente, Leandro Teodoro (2017, p. 129) identificou em Castela e em Portugal uma importante circulação de obras endereçadas justamente no modo como homens e mulheres deveriam se portar socialmente sob os moldes de uma vivência cristã. Francesc Eiximenis, franciscano catalão, escreveu entre os anos de 1330 e 1409 uma série de aconselhamentos que os fiéis deveriam seguir para que possuíssem uma formação moral. Desde considerações referentes à necessidade de defenderem a fé católica daqueles interessados em blasfemá-la, até conselhos que buscavam consolidar um dos principais mandamentos, amar ao próximo, predominou no seu discurso o interesse em construir as bases morais sob um forte teor religioso.

A linguagem torna-se, portanto, uma importante ferramenta para a compreensão do modo como a civilidade foi pensada no século XVI, sendo influenciada por valores morais combinados pelo interesse dos Estados em delimitar as funções de seus súditos, bem como da Igreja Católica em fazer com que essa relação estivesse sustentada a partir de valores também religiosos. Também por meio da linguagem, foi possível perceber quais padrões de masculinidade e feminilidade foram autorizados oficialmente nesse século. Em paralelo, a linguagem autorizada é exemplo de como predominou uma ambiguidade que marcou largamente a trajetória das mulheres não apenas no contexto europeu, principalmente por conta do interesse das estruturas de poder em demarcar quais 


\section{Escritas do Tempo/}

seriam as fronteiras, moralmente e religiosamente falando, a serem respeitadas pela figura feminina.

A consolidação do Diabo como grande inimigo da cristandade contribuiu igual e decisivamente para essa delimitação. Tal personagem, aliás, foi interpretado por Robert Muchemblend (2001, p. 116) como uma das principais ferramentas utilizadas por Igreja e Estados para reforçar a legitimidade de seus poderes frente aos fiéis que, ressalta-se, também eram súditos dos monarcas aliados ao poderio católico. A presença da feiticeira pode ser entendida, assim, como uma via de mão dupla, em que a sociedade reconhecia sua existência ao mesmo tempo em que representava um dos grandes exemplos das consequências decorrentes da ruptura com as fronteiras morais definidas para as mulheres.

Logo, não somente a manutenção de uma moralidade católica foi aspecto determinante para as mulheres, mas a sustentação dessa honra acabou por se tornar condicionante recorrente para a manutenção da ordem social dominante. A feiticeira foi, por consequência, uma das principais figuras utilizadas como exemplo de mulheres que rompiam com as fronteiras morais determinadas a elas. Entender nesse item a forma como o mundo português foi organizado é, portanto, compreender como esse discurso em torno da honra feminina foi definido e circulou pelos diversos espaços pertencentes a esse recorte. Implica, também, em identificar como todo um universo patriarcal teve sustentação a partir dos discursos aqui analisados, em que a noção de honra vinculada à submissão das mulheres aos homens era defendida.

Desta forma, não apenas o patriarcado é exemplo da pretensão de uma heterossexualidade hegemônica, mas, também, a misoginia pertencente a esse processo. Em outras palavras, predominou nesse contexto uma série de argumentos que, por meio de tratados morais, religiosos e medicinais, buscaram assegurar o ideal de submissão das mulheres aos homens sob a justificativa de uma suposta (e natural) inferioridade feminina.

\section{A formatação do delito da feitiçaria: poderes régios, episcopais e inquisitoriais}

O conceito de magia foi definido por Marcel Mauss (1950, p. 53) para além dos entendimentos de "seus atores ou por seus espectadores". O autor buscou valorizar, assim, a forte carga subjetiva que, segundo o próprio, está relacionada às múltiplas versões existentes sobre esse conceito nos mais variados contextos. A figura do mágico, defende 


\section{Escritas do Tempo/}

o autor, é definida mediante uma série de padrões que o caracterizam, em especial o aspecto físico e a sua condição social. Para as mulheres, no entanto, Mauss (1950, p. 63) não considera esses elementos como fatores determinantes para a sua associação à feitiçaria, valorizando, assim os "sentimentos sociais suscitados por suas qualidades" que as tornaram "reconhecidas em toda parte como mais aptas à magia que os homens". Podese afirmar, portanto, que o autor entende a progressiva construção de um consenso social como o maior responsável por conferir realidade à figura da feiticeira.

Carlo Ginzburg (2001, p. 90) entende o processo de construção da figura da feiticeira como sinônimo de uma verdadeira atmosfera de conspiração direcionada primeiramente aos leprosos e judeus para, no século XVI, se direcionar amplamente às bruxas, resultando em uma verdadeira "imagem obsessiva do complô montado contra a sociedade". Para o autor, foi nos Alpes ocidentais que surgiram as primeiras narrativas que buscaram comprovar a existência de verdadeiras seitas, compostas por homens e mulheres, que se reuniam cerimonialmente em torno da figura do diabo.

Segundo o historiador italiano, a imagem da feiticeira/bruxa no Ocidente europeu não se limita aos estereótipos míopes resultantes das análises tradicionais sobre essas personagens. Ir além desses estereótipos é compreender "um complexo fenômeno de interação, que não pode ser reduzido a pura e simplesmente projetar sobre os acusados obsessões antiquíssimas e recorrentes" (GINZBURG, 2001, p. 98).

Tendo em vista a existência de um intrincado jogo de interpretações, práticas individuais e/ou coletivas e uma longa tradição discursiva interessada em debater sobre a feitiçaria e suas nuances - incluindo os posicionamentos teóricos acerca desse fenômeno -, a análise neste item estará voltada para a linguagem empregada pelos juristas, tratadistas e autoridades religiosas portuguesas que se debruçaram sobre esse fenômeno e que também integraram o processo de conformação da feitiçaria à presença das mulheres como suas maiores praticantes. Com o avanço dos estudos de gênero também no campo das análises referentes ao fenômeno de "caça às bruxas", uma das principais reorientações dessas pesquisas consistiu, segundo Claudia Optiz-Belakhal (2009, p. 96), em avaliar quais as condições que propiciaram a perseguição majoritária às mulheres no âmbito da feitiçaria. 


\section{Escritas do Tempo/}

O já mencionado caráter de foro misto que a feitiçaria adquiriu no contexto português é um aspecto essencial para a compreensão desse delito. Esta caracterização está relacionada ao interesse demonstrado pela Coroa portuguesa em relação a esse fenômeno, tornando-se assunto recorrente, por exemplo, nas já citadas Chancelarias Régias, que reúnem uma importante documentação referente às feiticeiras residentes em Portugal.

Em 1501, o doutor Gonçalo de Azevedo apresentou a súplica de Branca Gil, "mulher velha e viúva, moradora em Lagos", na qual, por crença de estar servindo à Deus, utilizava as orações católicas nas benzeduras que promovia. Seu relato também deixa evidente o rigor da justiça civil no combate a essas práticas heterodoxas: "por bem do qual andava amorada com temor das nossas justiças e por lhe haverem de prender" (D’AZEVEDO, 1894, p. 332).

Entretanto, ainda que as Chancelarias correspondam a um importante exemplo do interesse da justiça civil para com as práticas mágico-religiosas, residem nas Ordenações os maiores exemplos de como essa perseguição vigorou não apenas no campo religioso. Daniela Calainho (2008, p. 212-213) destacou o peso conferido pelas Ordenações Afonsinas à feitiçaria, demonstrando como o Estado buscou aprimorar seus mecanismos de perseguição frente àqueles que diziam provocar malefícios, ou praticar curas e adivinhações. As penas variavam desde o pagamento de multas até a determinação de açoites em locais públicos, ou mesmo marcações no corpo feitas com ferro e brasa. Com a promulgação das Ordenações Manuelinas, a feitiçaria adquiriu maior consistência conceitual entre os juristas.

O quinto livro compila as discussões referentes às práticas direcionadas ao sobrenatural, conferindo maior peso aos indivíduos que se relacionavam com o Diabo. "Dos feiticeiros e das vigílias que se fazem nas Igrejas" corresponde ao trigésimo terceiro Título, disposto em cinco páginas, que versam sobre os "endemoninhados" e os indivíduos que praticavam toda a sorte de rituais mágico-religiosos.

Destaca-se o notável avanço das Ordenações Manuelinas ao tipificarem esse delito com maior profundidade, ainda mais se comparadas aos códigos jurídicos anteriores, como as Ordenações Afonsinas. Segundo Francisco Bethencourt (2004, p. 259), não somente a categorização aparece de modo mais claro, mas, também, a presença de uma descrição mais pormenorizada das práticas pertinentes ao campo da feitiçaria, bem como as penas correspondentes à prática desse delito. Quando analisado o conteúdo 
desse código jurídico, percebe-se a preocupação dos juristas em abranger o maior número de práticas que pudessem ser enquadradas a partir desse delito:

Outrossim não seja alguma pessoa tão ousada, que para adivinhar lance sortes, nem varas, para achar, nem veja em agua, ou em cristal, ou em espelho, ou em espada, ou em outra qualquer coisa luzente, nem em espadua de carneiro, nem façam para adivinhar figuras, ou imagens algumas de metal, nem de qualquer coisa, nem se trabalhe de adivinhar em cabeça de homem morto, ou de qualquer animaria, nem traga consigo dente, nem baraço de enforcado, nem qualquer outro membro de homem morto, nem faça com as ditas coisas, ou cada uma delas, nem com outra alguma (posto que aqui não seja nomeada) espécie alguma de feitiçaria, ou para adivinhar, ou para fazer dano a alguma pessoa [...]. ${ }^{14}$

No entender dos juristas, era essencial judicializar todo tipo de rito que fosse promovido sem a presença de um sacerdote e desvinculado de um código de crenças prescrito pela Igreja. Ademais, esclareciam: “e isso mesmo qualquer pessoa, que em círculo, ou fora dele, ou em encruzilhada, espíritos diabólicos invocar, ou a alguma pessoa der a comer, ou beber qualquer coisa para querer bem, ou mal a outrem, ou a outrem a ele, morra por ele morte natural. Pero nestes dois casos sobreditos não se fará execução" 15 .

Estes trechos também revelam como as instituições seculares encamparam o discurso demonológico, o que, segundo Stuart Clark (2006, p. 697), indica a existência de um grande consenso jurídico-religioso referente à capacidade de determinados indivíduos delimitarem os cenários passíveis de participação demoníaca. Embora a pena de morte aos acusados desse delito fosse geralmente descartada nas Ordenações, é interessante observar os trechos retirados desse conjunto jurídico, já que as preocupações lusitanas frente à presença do Diabo estavam inseridas em um amplo contexto referente ao debate acerca desse personagem.

Clark (2006, p. 705) ainda destaca que, não raro, a figura do magistrado assumiu maior proeminência na construção de interpretações e penas referentes às "cabeças de magos e bruxas". Na Alemanha, por exemplo, foi recorrente a defesa de que os príncipes e demais magistrados deveriam ser protagonistas na perseguição aos que se relacionavam com essa figura.

Vale ressaltar, também, que não apenas as Chancelarias Régias e as Ordenações Manuelinas representaram a presença secular no debate referente à feitiçaria. José Pedro Paiva (1997, p. 21) reuniu 9 corpos documentais que se debruçaram sobre esse tema desde

\footnotetext{
${ }^{14}$ Ordenaçoens do Senhor Rey D. Manoel. Tomo III. Livro V. Título XXXIII, p. 92-93.

${ }^{15}$ Ordenaçoens do Senhor Rey D. Manoel. Tomo III. Livro V. Título XXXIII, p. 92.
} 


\section{Escritas do Tempo/}

o século XVI, mencionando os códigos legislativos (incluindo os Regimentos inquisitoriais) até os mais diversos comentários que foram publicados a respeito das leis vigentes no período. Destacou a importância dessa literatura por ser capaz de revelar as opiniões de juristas que, por vezes, eram acompanhadas de exemplos da vida cotidiana. Também conferiu peso aos tratados de medicina, especialmente para o século XVII, em que "eram comuns referências a doenças de origem oculta que se acreditava serem provocadas por acção mágica".

Tamanha diversidade resultou, por sua vez, na sobreposição das instâncias jurídicas seculares e religiosas sempre que foi necessário tomar alguma decisão referente aos acusados por esse delito. De acordo com Francisco Bethencourt (2004, p. 43), não somente as interpretações variaram, mas, também, as estratégias que foram aplicadas para as acusações que chegavam diante das autoridades. Ainda que ambas as instâncias, civis e religiosas, tenham transformado a "feiticeira e o mágico, enquanto desclassificados religiosos, em desclassificados sociais", tendo encarado a feiticeira como antítese à normatização prescrita para as mulheres, prevaleceu uma discordância a respeito das formas que entrelaçavam heresia e feitiçaria.

Embora, para o mundo português, o peso referente ao delito da feitiçaria tenha sido tímido por parte dos tribunais religiosos, se comparado aos demais contextos europeus em que a perseguição foi mais bem articulada e com maior amplitude, não significa afirmar que essas instâncias não tenham se preocupado com essa temática. A presença de uma relativa tradição jurídica portuguesa interessada em discutir a presença de indivíduos que, ilicitamente, se relacionavam com práticas sobrenaturais, principalmente as que possuíssem traços de participação do diabo, corrobora essa assertiva. Além disso, destaca-se o ingresso das justiças inquisitorial e a episcopal nesse debate, na medida em que a feitiçaria foi conceito discutido entre as autoridades seculares e religiosas, bem como se tornou um delito pertencente ao rol de atuação de ambas as instâncias, embora o Santo Ofício tenha tomado as rédeas a respeito de qual justiça seria a responsável por estabelecer processos e sentenças.

Diante do avanço dessa instituição, a atuação das justiças episcopais se direcionou para a função de avaliar e, caso necessário, corrigir, os erros morais, principalmente os casos envolvendo amancebamentos, além dos erros de caráter sexual, como a prostituição e a alcoviteirice. Por esta razão que a diocese de Coimbra, analisada por José Pedro Paiva (1994), apresentou 59\% desses casos, enquanto que no Algarve os números chegaram na 


\section{Escritas do Tempo/}

casa dos 91,5\%. Todavia, é errôneo afirmar que esses religiosos tenham simplesmente abandonado o debate a respeito da feitiçaria, ou que não tenham se debruçado em episódios envolvendo práticas que eram entendidas a partir desse delito. Um dos principais exemplos desta ressalva consiste na atuação encabeçada por Bartolomeu dos Mártires no Arcebispado de Braga, já que se tratou de uma região em que o número de episódios relacionados à feitiçaria foi relevante, mesmo diante da presença cristã-nova.

A atuação desse arcebispo é exemplo, segundo Paiva (1997, p. 59), capaz de relativizar a ideia na qual a hegemonia do Santo Ofício frente à perseguição aos crimes de fé não teria resultado, por consequência, em uma série de conflitos jurisdicionais, principalmente com o âmbito episcopal. Juntamente com d. Manuel de Meneses, d. António Pinheiro e d. Constantino Barradas, a figura de Bartolomeu dos Mártires é citada como exemplo de "antístites que continuaram a abrir feitos contra heréticos nos seus auditórios", ainda que a contragosto dos inquisidores. Já em trabalho mais recente, Juliana Pereira (2017), que antes analisou o contexto de atuação do religioso frente à visitação inquisitorial promovida por Pedro Álvares de Paredes no Arcebispado de Braga, ampliou a ótica de suas análises ao perceber a relação direta do religioso com o Tribunal do Santo Ofício.

A autora notou que o arcebispo assumiu, durante o Concílio de Trento e diante de outras autoridades, não apenas inquisitoriais, a defesa de um modelo alternativo para lidar com os delitos de caráter religioso. A feitiçaria foi, assim, uma das principais questões que percorreram as reflexões de Bartolomeu dos Mártires, incluindo os seus escritos a respeito da Summa Teológica, de Tomás de Aquino (PEREIRA, 2017, p. 180).

A necessidade, segundo o religioso, de investigar "o que a alma sente acerca do poder do demônio" demarca, tal qual defendeu a autora, o modo como o mesmo entendeu o delito da feitiçaria (2017, p. 108). A gravidade das práticas envolvendo a invocação de demônios era mensurada a partir da crença daqueles que buscavam tais criaturas para a resolução das mais variadas questões: “é presumido herético e será verdade nestas coisas, se o coração conforma pelo dito ou pelo feito". O que prevaleceu em primeiro plano na argumentação do antístite a respeito da existência ou não de uma possível natureza herética foi, segundo a autora, a "afronta à autoridade e aos ensinamentos da Igreja, engano e questionamento do poder e conhecimento reservados a Deus" (PEREIRA, 2017, p. 180-181). 


\section{Escritas do Tempo/}

Com o avanço do Santo Ofício no monopólio de perseguição ao delito da feitiçaria, a consequência prática para a atuação episcopal foi a progressiva mudança na própria atuação dos bispos frente os crimes maiores - como o judaísmo e o protestantismo - e os menores - no qual a feitiçaria estava enquadrada. Essa migração para o âmbito inquisitorial foi justificada, no entender de José Pedro Paiva (2011, p. 44), pela pressão régia que via com bons olhos essa alteração, além da influência e hegemonia cada vez mais evidentes por parte da Inquisição. Ademais, sintetizou a também crescente supremacia do Santo Ofício frente à matéria das heresias "porque os bispos a aceitaram e desde cedo estiveram ideologicamente conformados com esse projecto" (PAIVA, 2011, p. 427).

Talvez o contraponto a essa afirmação seja o próprio percurso que Bartolomeu dos Mártires construiu frente ao delito mencionado, mais precisamente nos episódios resultantes da visitação promovida por Pedro Álvares de Paredes ao Arcebispado bracarense, em 1565. Como bem destacou Juliana Pereira (2017, p. 113), não foram poucos os episódios em que o antístite tratou da feitiçaria. Nas suas palavras, "o dominicano vertia boa quantidade de tinta para tratar dos delitos de feitiçaria e luteranismo", o que influenciou diretamente nos rumos que a visitação citada tomou, tendo em vista que ambos os delitos foram os mais denunciados pela população.

Compete destacar, como o fizera a autora, que a atuação do religioso era anterior à presença do visitador no Arcebispado, sendo caracterizada, inclusive, por admoestações públicas. Esse posicionamento possibilita o alargamento do olhar com relação às estruturas normativas que se debruçaram nas práticas entendidas por feitiçaria, interessadas em sedimentar o rol de atuação e de regulação das vivências sociais, principalmente entre as mulheres.

Mas, de fato, é no contexto de atuação inquisitorial que são encontrados os maiores registros referentes à feitiçaria no mundo português, incluindo aí os documentos oficiais, como os processos caracterizados pela presença desse delito e estabelecidos pelos inquisidores a partir de 1541. A existência dessa documentação permite que o leitor visualize tanto um painel quantitativo dessa perseguição, como as diversas trajetórias de homens e, principalmente, mulheres, que foram processados ao longo dos séculos de vigência dessa instituição.

Francisco Bethencourt (2004, p. 285) conclui que, num universo global de atuação do Santo Ofício, esses processos não ultrapassaram a casa dos $2 \%$. Juntamente com esse 


\section{Escritas do Tempo/}

baixo número, o teor das sentenças, em que nenhum indivíduo acusado de feitiçaria foi relaxado ao braço secular, corrobora com o entendimento de que esse delito foi acompanhado de uma "brandura inquisitorial", tanto nas investigações como nos desfechos das mesmas. Quanto ao que chamou de "especialização temporária" da Inquisição eborense, a principal justificativa, a seu ver, se deu por conta da presença em Évora do Inquisidor-geral e cardeal d. Henrique, local em que exercia a função de arcebispo: "Daí a maior clareza no reconhecimento de presos e na troca de informações" (BETHENCOURT, 2004, p. 283).

A respeito da relação entre o delito da feitiçaria, sua perseguição pelo Santo Ofício e a presença das mulheres, o autor identificou para o século XVI que 72,3\% dos processos estabelecidos sob essa relação foram direcionados à figura feminina. Em números absolutos, 68 mulheres foram processadas, cabendo à Inquisição de Évora - com 50 processos - novamente o protagonismo. A primeira justificativa apontada pelo autor é consoante a uma das hipóteses trabalhadas nesse artigo, ou seja, que a predominância de mulheres processadas por feitiçaria está atrelada à "imagem tradicional da delinquência - o crime simbólico, ou seja, o encantamento perigoso ou o mau-olhado, seria praticado por mulheres" (BETHENCOURT, 2004, p. 283).

Acerca do modo como as autoridades inquisitoriais atuaram no combate à feitiçaria, incluindo aí os contextos de produção dos processos (denúncias, confissões, arguições e sentenças), a obra de Francisco Bethencourt é relativamente lacunar. Nos poucos momentos em que dissertou a respeito dessa questão, apontou para a percepção que o Santo Ofício possuiu a respeito das práticas mágico-religiosas como "fenômeno religioso ilícito, designando explicitamente o ensino de conjuros ou feitiços como atos de dogmatização" (BETHENCOURT, 2004, p. 206).

Talvez a sua dificuldade em tratar do assunto tenha sido ocasionada pelo fato de que o tema da feitiçaria, do diabo e seus prodígios, terem sido matéria de preocupação teórica, e não necessariamente prática, com maior recorrência entre tratadistas, teólogos e padres que não estavam vinculados à Inquisição. E, mesmo quando debatidos, esses temas não estavam isolados, pelo contrário, eram acompanhados de reflexões mais amplas a respeito do catolicismo, da doutrina a ser seguida e do modo de vida religioso que os fiéis deveriam acompanhar. ${ }^{16}$

\footnotetext{
${ }^{16} \mathrm{O}$ autor cita, por exemplo, o Breve memorial de pecados, de autoria de Garcia Resende, o Memorial de pecados, do frade António de Beja, o Tractado de Penitencia, escrito por d. Sancho de Noronha e a
} 


\section{Escritas do Tempo}

\section{Considerações finais}

Este trabalho analisou como padrões de feminilidade e masculinidade foram construídos no mundo português por meio de um discurso moralista secular e religioso, pelo qual foi possível visualizar o cenário normativo decorrente deste discurso, cuja defesa do ideal de submissão das mulheres aos homens foi predominante. Este cenário foi caracterizado pela existência de um modelo ideal de mulher em que a honra, a submissão e a vida doméstica foram elementos recorrentes.

Os textos oficiais referentes às mulheres, sejam os provenientes da literatura jurídico-secular ou os de cunho moral e religioso, buscaram sintetizar uma série de formatos compreendidos pelo universo dos homens a respeito dos modelos ideais de comportamento por eles almejados. Pretenderam, também, estabelecer quais seriam as fronteiras de comportamento prescritas para as mulheres, a fim de que mantivessem os princípios morais oficialmente aceitos à época. Vale citar o amplo entendimento entre os tratadistas e os juristas desse período de que a figura feminina representava a ambiguidade, transitando entre a divindade e a perdição.

Essa lógica normativa esteve presente no mundo português, compondo o profundo quadro de discussões jurídicas e religiosas interessadas em consolidar o tecido social, as hierarquias, funções e diferenças sexuais entre homens e mulheres. Assim, foi possível observar ao longo deste trabalho como os discursos morais e religiosos produzidos e difundidos no mundo português a partir de uma série de indivíduos - tratadistas, juristas, médicos e o clero em geral -, contribuíram decisivamente para a formatação dos padrões de masculinidade e feminilidade direcionados aos homens e mulheres inseridos nesse espaço.

Visualizou-se, também, como essa formatação correspondeu aos princípios hierárquicos e excludentes característicos da organização social presente no mundo português. Por consequência, conclui-se que esses princípios marcaram amplamente a formação de uma unidade do gênero pautada na heterossexualidade compulsória, responsável pela produção desses padrões a partir do entendimento de que a ordem social só seria mantida através da submissão das mulheres aos homens. Cabe defender, portanto, que a unidade da experiência do gênero, do sexo e do desejo no mundo português foi

Doctrina de princípios e fundamentos de christandade, de d. João de Melo. Cf. BETHENCOURT, 2004, p. 239. 


\section{Escritas do T EMPo/}

marcada por um discurso patriarcal e misógino, cujo maior interesse de quem a produziu e difundiu foi a manutenção de uma "heterossexualidade institucional" (BUTLER, 2016, p. 52).

Quando essas mulheres não corresponderam às expectativas de gênero existentes, ou seja, aos ideais de honra e recato, foram apontadas como indivíduos alheios às sociedades, passíveis de acusação, sendo algumas das suas identidades interpretadas a partir do delito da feitiçaria, muito por conta das crenças existentes. É a partir desse argumento, aliás, que se torna perceptível a necessidade de os historiadores aprofundarem as discussões referentes ao modo como o Santo Ofício português atuou nesse processo, a fim de que a perseguição à feitiçaria no mundo português seja compreendida como um fenômeno generificado (BLÉCOURT, 2000, p. 299), ${ }^{17}$ pautado por relações desiguais de poder e pela tentativa de definição dos papeis sociais destinados às mulheres a partir de uma estrutura que se pretendia homogênea.

\section{Referências}

BAILEY, Michael. The Feminization of Magic and the Emerging Idea of the Female Witch in the Late Middle Ages. Essays in Medieval Studies, v. 19, pp. 120-134, 2002.

BARSTOW, Anne. On Studying Witchcraft as Women's Story. Historiography of the European Witch Persecutions. Journal of Feminist Studies in Religion, v. 4, n. 2, pp. 719, 1988.

BETHENCOURT, Francisco. $O$ imaginário da magia: feiticeiras, adivinhos e curandeiros em Portugal no século XVI. São Paulo: Companhia das Letras, 2004.

BLÉCOURT, Willem. Early modern European witchcraft. Reflections on witchcraft and gender in the Early Modern Period. Gender \& History, v. 12, n. 2, pp. 287-309, 2000.

BRAGA, Isabel Mendes Drumond; MOURÃO, Maria Elsa. Gênero e discurso proverbial no Portugal Moderno. Faces de Eva, n. 33, pp. 83-102, 2015.

BUTLER, Judith. Problemas de Gênero: feminismo e subversão da identidade. Trad. de Renato Aguiar. Rio de Janeiro: Civilização Brasileira, 2016.

CALAINHO, Daniela Buono. Metrópole das mandingas: religiosidade negra e inquisição portuguesa no Antigo Regime. Rio de Janeiro: Garamond, 2008.

\footnotetext{
${ }^{17}$ Uma heresia que, nas palavras de Tamar Herzig (2010, p. 69), esteve diretamente relacionada ao gênero.
} 


\section{Escritas do Tempo/}

CLARK, Stuart. Pensando com Demônios. A ideia de bruxaria no princípio da Europa Moderna. Trad. de Celso Mauro Paciornik. São Paulo: Editora da Universidade de São Paulo, 2006.

D'AZEVEDO, Pedro A. Benzedores e feiticeiros no tempo D'El Rei Dom Manuel. Revista Lusitana. Porto, v. 2, n. 3, 1894.

DELUMEAU, Jean. História do medo no Ocidente. 1300-1800. Uma cidade sitiada. Trad. de Maria Lúcia Machado. Rio de Janeiro: Companhia das Letras, 2009.

GINZBURG, Carlo. História Noturna: decifrando o Sabá. 2. ed. São Paulo: Companhia das Letras, 2001.

HESPANHA, António Manuel. Imbecilitas: as bem-aventuranças da inferioridade nas sociedades do Antigo Regime. São Paulo: Anablume, 2010.

LENCART E SILVA, Maria Joana Corte-Real. A mulher nas Ordenações Manuelinas. Disponível em: http://ler.letras.up.pt/uploads/ficheiros/6384.pdf. Acesso em: 19/03/2019.

LEVACK, Brian P. A caça às bruxas na Europa Moderna. Trad. de Ivo Korytowski. Rio de Janeiro: Campus, 1988.

LÓPEZ-SALAZAR, Ana Isabel; OLIVAL, Fernanda; FIGUERÔA-RÊGO, João (orgs). Honra e Sociedade no mundo ibérico e ultramarino. Inquisição e Ordens militares. Séculos XVI-XIX. Lisboa: Caleidoscópio, 2013.

MARCOCCI, Giuseppe; PAIVA, José Pedro. História da Inquisição portuguesa: 15361821. Lisboa: A esfera dos livros, 2013.

MAUSS, Marcel. Sociologia e Antropologia. Trad. de Paulo Neves. São Paulo: Cosac \& Naify, 1950.

MUCHEMBLEND, Robert. Uma história do Diabo. Rio de Janeiro: Bom Texto, 2001. Ordenaçoens do Senhor Rey D. Manoel. Livro II. Coimbra: Real Imprensa da Universidade, 1797.

Ordenaçoens do Senhor Rey D. Manoel. Livro V. Coimbra: Real Imprensa da Universidade, 1797.

OPITZ-BELAKHAL, Claudia. Witchcraft Studies from the Perspective of Women's and Gender History. Magic, Ritual, and Witchcraft, vol. 4, n. 1, p. 90-99, 2009.

PINTO, Frei Heitor. Imagem da vida cristã. (1563-1572). 2. ed. Lisboa: Livraria Sá da Costa, 1958.

PAIVA, José Pedro. Práticas e crenças mágicas: o medo e a necessidade dos mágicos na diocese de Coimbra (1650-1740). Coimbra: Minerva-história. 1992. 


\section{Escritas do Tempo/}

Bruxaria e superstição num país sem "caça às bruxas”: 1600-1774. Lisboa:

Editorial Notícias, 1997.

PATRIARCA, Raquel. A presença das mulheres nas Ordenações Afonsinas, Manuelinas e Filipinas: uma visão evolutiva. In: ALVIM, Maria Helena Vilas-Boas; COVA, Anne; MEA, Elvira Cunha de Azevedo. Em torno da História das mulheres. Lisboa: Universidade Aberta, 2002.

PEREIRA, Isaías da Rosa. Processos de Feitiçaria e de Bruxaria na Inquisição de Portugal. Cascais: s/e, 1976.

PEREIRA, Juliana Torres Rodrigues. Um Arcebispo em defesa do poder episcopal: as relações entre D. Frei Bartolomeu dos Mártires e o Santo Ofício Português (1559-1582). Tese (Doutorado em História) - Universidade de São Paulo. São Paulo, 2017.

PROSPERI, Adriano. Tribunais da Consciência: Inquisidores, Confessores, Missionários. Trad. de Homero Freitas de Andrade. São Paulo: Editora da Universidade de São Paulo, 2013.

ROPER, Lyndal. Oedipus and the Devil. Witchcraft, sexuality and religion in early modern Europe. London: Taylor \& Francis e-Library, 2005.

ROWLANDS, Alison. Witchcraft and Gender in Early Modern Europe. In: LEVACK, Brian (org). The Oxford Handbook of Witchcraft in Early Modern Europe and Colonial America. Oxford: Oxford University Press, 2003.

SCOTT, Joan Wallach. Gênero: uma categoria útil de análise histórica. Educação \& Realidade. Porto Alegre, v. 20, n. 2, p. 71-99, jul-dez/1995.

TEODORO, Leandro Alves. Instruções religiosas para o bem falar (Portugal/Castela séculos XIV e XV). Tempo. Niterói, v. 23, n.1, p. 126-138, abr. 2017.

WIESNER-HANKS, Merry E. Gender and History. New perspectives on the past. Malden, Massachusetts: Blackwell Publishers, 2001.

Artigo recebido em 30 de março de 2019 e aprovado em 15 de junho de 2019. 